that they are unimportant, and that they exercise no considerable control over disease or its developments. Had such been ever the practice of physicians, our profession would have had a firmer hold on the affection and respect of the people than it has at present, and the upright, conscientious practitioner, who, seeing no occasion for a prescription, says so, and gives none, would not be liable, as now, to have his patient, with his often much-needed fees, slip into the hands and pocket of some more knowing brother, who soothes with genial placebo the physic-craving fancy of the patient, or some charlatan who with his mystic globules accomplishes the same benevolent object.

[To be continued.]

NEW STAND FOR THE COMPOUND MICROSCOPE.

BY O. W. HOLMES, M.D.

[From the Proceedings of the department of Microscopy of the Boston Society of Natural History, Ang., 1857.]

The more especial object of this mechanical arrangenent is to facilitate the use of the direct light of a lamp placed close to the object. Many of our microscopists must hare seen Mr. Spencer use a lamp in this way, holding it in his hand and rarying the distance and obliquity so as to produce the particular effect desired. The advantages of direct light are its easy management, its brilliant effects, and the more perfect definition it gives of delicate objects. But, inasmuch as the heat and smoke of the lamp ascend, this method of illumination can only be used with the microscope-tube (or compound body) in the horizontal or mode. rately inclined position, unless the lamp be so far removed as to lose its peculiar advantages. It is evident that the lamp cannot be used at all with the tube rertical and directly over it.

If an instrument is to be employed in the horizontal or slightly inclined position, it will require a stage movement; otherwise both hands will be needed to move the object, and will even then find it awkward to do so, as the object must be secured to prevent its sliding. Again, if the stage is inclined, and the lamp close to it, it is evident that the broader the stage the more it overhangs the lamp, and the more it is exposed to its smoke and heat. By mak. ing the stage open at top, like a horseshoe, we get rid of this dif. ficulty entirely.

An instrument that answers this special object alone, namely, the use of direct light, can be made, on the general plan of the one I show the Society, with great ease, and at small expense. But as it is sometimes necessary or convenient that the object should be placed horizontally and the microscope-tube verticallyas in examining fluids with low powers, or opaque bodies-certain additions have been made to this model to render it capable of 
being so used; reflected light, or the use of the condensing lens, being substituted for the mode of illumination for which it is specially adapted. This, of course, involves the expense of a mirror and lens with their adjustments, which is, however, trifling, if the plan here shown is followed.

The instrument is represented in working order in figure 1.

The base of the whole is a box made of black walnut, three quarters of an inch thick, having two uprights, of the same material and thickness, firmly screwed to the inner edges of the strips which partly cover it. On each side of these uprights, over these partial covers, are screwed two thick pieces of black walnut, with holes for the eyeglasses on one side and the objectives on the other.

This box is open at one end to receive a flat-iron or other weight, if required, and to admit the other parts when the instrument is packed.

Between the uprights is

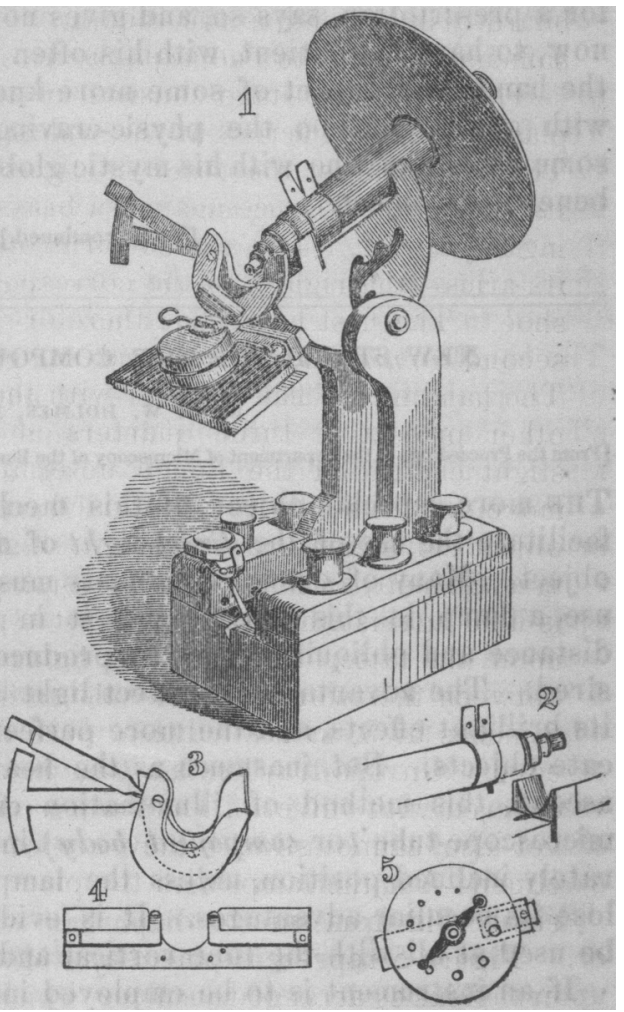
received the bearing semicircle, made of three pieces of black walnut glued together, the inner one having the grain directed lengthwise, the two outer ones rertically. This is provided with a "slot" partly vertical, partly horizontal, and several notches. A binding screw holds it at any angle and at various heights between the uprights.

The microscope-tube, made heavy by a leaden tube inside, is laid upon two V-shaped supports cut out of the wood, being held solely by its weight when used in the horizontal or inclined po. sition.

The microscope-tube has a ring an inch wide, fitting tight, but beco:ing loose ou pressing its handles, and having a little projection or spur on the side opposite its handles, as shown in figure 2 .

Th: anterior V-shaped support is also shown in this figure. It has a piece of brass let into the wood for the spur on the ring to 
play against. As the posterior surface of this support is slanted about one sixteenth of an inch, it is evident that in turning the tube through a semicircle it will adrance or recede that distance. This turning of the tube is performed by means of the black pasteboard disk clasped to the tube near the eye-piece, which makes a suffici ntly delicate fine adjustment.

The horseshoe stage consists of two pieces of brass, cast and planed, 4 inches across at the widest part, and 3 inches in height. The first, nearest the observer, turns on a screw at the centre of its semi-circumference against a brass plate screwed to the bearing semicircle. The second turns on a screw which unites one of its arms-the right-to the corresponding arm of the first horseshoe. The first horseshoe therefore carries the other with it; the second turning very easily, is moved independently of the first. The handles are flat, the one with the cross next the observer, the other projecting three quarters of an inch beyond it, so that a slight change of the thumb determines whether one alone shall move, and the object be carried up and down, or both, and the object more from side to side. Figure 3 shows the principle of arrangement, and figure 4 the object-holder with its springs, which is held against the horseshoe by a piece of brass plate screwed upon the latter, as shown in figure 1-the object-holder sliding between the two. The tray that holds the lamp is of sheet-iron, 5 inches by 3 , with a ledge of half an inch in width at its remote edge. On this tray rests a thin piece of wood of the same size, covered with velvet. The lamp haring its hase covered with velvet also, cannot slide off, even when the microscope is much inclined-but the lamp, with the piece of wood on which it rests, is easily slid from side to side.

Figure 5 represents the diaphragm with the achromatic condenser. This is arranged in place by sliding its foot under a spring upon the same piece of wood to which the tray for the lamp is fustened.

The dimensions of various parts not yet giren are as follows: Inside dimensions of the box, length 8 inches; width 5 ; height 2 ; from bottom of inside of box to binding screw, 11 inches. Distance between uprights 15 inches. Bearing semicircle same thickness. Radius of this semi ircle $3 \frac{1}{4}$ inches. Object-holder $7+2$. Diaphragm 3 inches in diameter.

If desired to use the microscope in the rertical position, the tule must be held firmly against the supports, the tray removed, and the mirror represented in figure 1 brought into its place. A loose ring of plate brass capable of being made fast to the bearing semicircle serres to fix the tube. The mirror is a plane one, set in an open frame. If a plano-ionrex lens is placed orer it, it acts like a concave inirror; if the inirror is remored, the same lens nay be used as a condenser. 
In packing this instrument, the tray and diaphragm go at the bottom of the box, the bearing semicircle is held by the bindingscrew hetween the uprights, and the pasteloard disk is held at the side of one of the uprights. The lamp and other accessions go into the box.

The leading peculiarities and novelties of the instrument will now be indicated.

1. Union of stability and portability. The base gives a sufficient degree of steadiness for common purposes. But by sliding a common flat-iron into its interior it becomes as firm as the most ponderous instruments of Ross, which are too heary to be carried about with confort.

2. The facility with which the height of the compound bods, as well as its inclination, may be varied by means of the "slots" and notches in the bearing semicircle.

3 . The mode of focal adjustment by rotation of the tube, or compound body. This has a movable ring upon it with a projecting spur, which bears against the slightly inclined posterior surface of the anterior V-shaped support of the tube. The disk which protects the eyes is used as a lever, and thus a very smooth and uniform motion without the smallest amount of "lost time" or "lack lash" is obtained without rack and pinion, spring or screw.

4. The open horseshoe stage, with the movable object-holder received upon its remote (anterior or inferior) surface, the glass object-slide being itself pressed by springs against the remote surface of the object-holder. It follows from this arrangement, 1st. That if one object is in focus, all others mounted in a similar manner are in focus, or very nearly so; 2 d. That the thickness of the stage becomes practically reduced to nothing, as the glass side is next the lamp, and behind, or below, everything except the springs that press it forward against the remote face of the objectholder.

5. The double radial stage-movement. The horseshoe piece next the observer turns from side to side on a screw passing through the lower or middle portion of its arc. The other horseshoe piece turns on a screw fixing it to one arm of the first, so that it moves up and down. The arcs they follow form so small a part of a circle that the eye cannot distinguish their movement from a rectilinear one. The bolt and crnssbow flat handles, working singly or together, make the management of the stage-movement very convenient.

6. The flat-wicked lamp, so mounted as to move freely without the possilility of slipping, at whatever angle the apparatus may be inclined.

7. The combination of mirror and lens in an open frame, so 29, 
by slight alterations, to serve a triple purpose ; that of a plane mirror, of a condenser, and of a substitute for the concave mirror.

8. The sinple and effective mounting of the achromatic condenser and the diaphragm attached to it.

It remains for others to determine if any or all of these innovations are improvements.

\section{Heports of Hetical Societics.}

EXTRACTS FROM THE RECORDS OF THE MIDDLESEX EAST (MASS.) DISTRICT MEDICAL SOCIETY. BY E. CUTTER, M.D., SECRETARY.

Tre Middlesex East District Medical Society held its eighth annual meeting, Nov. 4th, at the house of Dr. J. Nelson, in Woburn. After the transaction of business and the election of officers for the ensuing year, Richard L. Hodgdon, M.D., and Joseph Underwood, M.D., both of West Cambridge, were chosen honorary members.

The following paper on a case of inversion of the uterus was then read by Dr. Truman Rickard, of Woburn.

Inversion of the Womb, complete, or even partial, is a very grave occurrence- " one of the most dangerous accidents that can happen to a lying-in woman." Our profession has reason to rejoice that the intelligent practitioner seldom knows anything of it, except what knowledge he derives from books. But cases now and then occur-melancholy cases-especially where our own personal friends are in peril, when the physicion is summoned in haste to witness, with a bleeding heart, the sad results ignorance has brought about, and to do what best he may, in the face of fearful odds, to correct the mischief, to stay the rapidly ebbing powers of life, and rescue the sufferer from the perilous position in which she is situated.

CASE. - On the evening of Sept. 7th, 1857, at about half past nine o'clock, I was requested to visit Mrs. C. I was informed that a midwife was in attendance-that the child was born several hours previous, but that there was trouble with the afterbirth. I subsequently learned that Mrs. C. was taken in labor at eleven o'clock on the evening of Sept. 6th, and that the child was born at five o'clock in the afternoon of Sept. 7th. Of the character of the labor I have no knowledge; but immediately following the birth of the child, she was very comfortable, and mutual congratulations were expressed by herself and husband in view of the favorable progress of affairs. The husband subsequently went to his office, and spent the usual time there. On his return home, in the latter part of the evening, he found that there was trouble-that the midwife had not succeeded in removing the placenta-and I was sent for. Upon entering the chamber, I found the attendant sitting by the patient and bathing her face with camphor. I took my seat by the patient, laid my finger upon the radial artery, and asked her how she did. She replied, "I don't know." Her appearance was as follows: face very pale, lips white, respiration sighing, pulse small, feeble and frequent. The midwife remarked to me that something was the matter; that she had almost got the afterbirth 